$$
\begin{gathered}
\text { 아이트래킹 평가 방법과 경관 형용사 평가 비교 연구 } \\
\text { - 대학 캠퍼스 야간경관을 대상으로 - } \\
\text { 강영은" · 김송이"* 백재봉"** }^{*{ }^{* *}} \\
\text { "동아대학교·"한국문화관광연구원 ·"부산대학교 }
\end{gathered}
$$

\title{
Comparative Study on Eye-Tracking Evaluation and Landscape Adjectives Evaluation \\ - Focusing on the Nightscape of a University Campus -
}

\author{
Kang, Young-Eun ${ }^{*} \cdot$ Kim, Song-Yi* $\cdot$ Baek, Jae-Bong ${ }^{\star \star *}$ \\ "Dong-A University, ${ }^{*}$ Korea Culture and Tourism Institute, ${ }^{* * * *}$ Pusan National University
}

\begin{abstract}
The purpose of this study is to improve the understanding of visual perception and to extend the landscape evaluation area by comparing eye-tracking evaluation and landscape adjective evaluation methods towards various type of nightscapes. As a result of the study, it showed that 'blink count', 'fixation duration average', and 'saccade duration average' of eye tracking measurements have a significant correlation with 'beautiful', 'interesting', 'accessible', 'satisfying', and 'safe' regarding landscape adjectives. In addition, there was a tendency toward areas of interests (AOIs) depending on 12 different nightscapes, which showed that the gaze was fixated by focusing on certain landscape elements such as 'door' and 'signs'.

These results suggest that the eye-tracking method is an effective tool to specify the evaluation of 'landscape elements' rather than the 'whole landscape' and can be used as a basis to support landscape preference theories, which has been presented as conceptual only. In this way, the results of this study demonstrated the possibility of various applications of eye tracking as an objective landscape evaluation technique, and it is possible to suggest specific implications to landscape planning through the accumulation of continuous research results.
\end{abstract}

Key Words: Landscape Planning, Landscape Perception, Eye Movement, Distribution of Attention

\section{국문초록}

본 연구는 다양한 야간경관의 특성을 파악하기 위하여 아이트래킹 평가 방법과 경관 형용사 평가 방법의 비교를 통하여 시지각적 경관 지각에 대한 이해를 높이고, 경관 평가 영역을 확장하기 위한 연구논문이다. 연구 결과, 캠퍼스 야간경관을 대상으로 한 아이트래킹 평가 결과에서는 '눈 깜빡임 수(Blink count)', '눈 응시 시간(Fixation duration) 평균',

${ }^{+}$: 이 논문은 부산대학교 기본연구지원사업(2년)에 의하여 연구되었음

Corresponding author: Song-Yi Kim, Korea Culture and Tourism Institute, Seoul 07511, Korea, Tel.: +82-2-2669-9800, E-mail: skimtheory@gmail.com 
‘시선의 급격한 이동시간(Saccade duration) 평균'과 경관 형용사 중 '아름다운', '흥미로운', '접근성이 높은', '만족하는', '안전한' 형용사와 유의미한 상관관계가 있음이 검증되었다. 또한, 캠퍼스 야간경관의 관심지역 분석 및 비교에서는 경관 특성별 관심영역이 달라지는 경향성을 파악하였으며, 특히 '문', ‘표지판' 등 특수 경관 요소에 집중하여 시선이 고정되는 것으로 도출되었다. 이상의 결과들을 통하여 아이트래킹 분석 방법이 '경관 요소'에 대한 평가를 구체화시킬 수 있는 효율적인 도구라고 판단하였으며, 기존 개념으로만 제시되었던 경관 선호 이론들을 뒷받침할 수 있는 근거로 활용될 수 있다는 측면도 의미 있는 결과라고 할 수 있다. 본 연구는 이처럼 객관적인 경관 평가 기법으로서 아이트래킹의 다양한 활용 가능성을 제안하였으며, 지속적인 연구 결과의 축적으로 경관계획에 구체적인 시사점을 제시할 수 있을 것이다.

주제어: 경관계획, 경관지각, 시선 이동, 주의 분산

\section{I. 서론}

경관이란 일차적으로 보여지는 풍경을 의미하며, 이차적으 로는 풍경에 내재하고 있는 자연생태계의 작용, 인간 활동 등 과 관련된 의미를 함축하고 있다(Im, 1991). 유럽의 경관 협회 (Council of Europe, 2000)에서는 이러한 경관을 자연과 인간의 상호작용으로 발생한 결과물로서, 인간에 의해 지각된다는 개 념으로 설명하고 있다. 즉, 경관은 지각되는 객체적 대상으로서 주체로서 인간의 지각이 함께 수반되어야 한다는 내용을 포괄 하고 있다.

경관 관리 및 지속가능성 문제에 대한 대중의 인식은 공간계 획을 비롯한 많은 분야에서 증가하고 있으며, 점차적으로 관 리자에게 더 큰 기대를 걸고 있는 추세이다(Pechanec et al., 2015). 경관이 도시의 매력을 증가시키는 주요한 요소이자, 그 자체가 경쟁력이 될 수 있기 때문이다.

이처럼 최근 높아지고 있는 경관의 대중적 관심과 함께 높아 져야 할 주제는 환경에 대한 인지 및 지각이다. 이는 우리를 둘 러싸고 있는 경관의 질을 향상시키고, 보전해야 할 경관의 우 선순위를 매기는 등 경관의 질을 평가하는 중요한 기준으로서 작용한다. 일반적으로 환경지각의 $87 \%$ 가 시각에 의존하고 있 기 때문에 일정 환경에서의 시각적 질은 이용자들의 환경에 대 한 시각적 선호에 달려 있다고 할 수 있다(Suh and Choi, 2012). 시각적 선호에 관련한 주요 연구들은 경관의 질이 경관의 생 물물리학적 특징과 인간의 주관적 인식 및 판단의 상호작용에 의해 결정된다는 전제를 가지고 있다(Tagliafierro et al., 2016). 또한, 경관에 관한 많은 분야의 연구에서 경관에 대한 사람들 의 선호도가 수렴되는 일정한 규칙이 존재하며, 임의적이지 않 다는 것을 보여주고 있다(Strobele and Hunziker, 2017). 이에 경관계획을 위한 객관적이고 합리적인 기준을 만들기 위해서 는 실험심리학적 접근을 통한 연구가 필수적이며, 이를 통하여 정량적인 기준을 도출할 수 있다( $\mathrm{Im}, 2008)$.

기존 경관 선호에 대한 연구들은 수경 요소, 녹지, 문화적 경 관 요소의 중요성 등 등 경관 평가 프레임 내 중점적으로 차지
하고 있는 경관 요소의 중요성 등 경관 요소의 전체적인 평가 에 치중해왔다. 이밖에 통일성, 복잡성 등 경관이 가지는 다양 한 속성을 실험하는 연구 혹은 경관 구성, 구도에 대한 연구가 (Pazahouhanfar and M.S., 2014; Kuper, 2017) 축적되고 있으 나, 조사자나 피조사자의 주관이 영향을 미칠 수 있다는 회의 론적 시각(Dramstad et al., 2006)도 존재하고 있는 실정이다.

한편, 경관선호에 관한 많은 연구들은 연구 지역 및 평가 요 소 등 유사한 주제를 다루었음에도 불구하고, 적용된 방법론 적 이질성으로 인해 종합적인 경관 선호 연구간 비교를 제한 함으로써, 교차 사례(Cross-case comparison)의 축적에 의한 발 전(Up-scaling) 가능성을 차단해왔다(van Zantan et al., 2014). 또한, 그들의 연구에서 경관 선호 조사는 상황에 따른 결과 (Context-based)를 주로 다루기 때문에, 경관 정책이나 실무 에서의 적용 가능성도 점차 배제되고 있다는 문제점을 제시한 바 있다.

그럼에도 한정된 공간 내 경제적, 환경적 측면에서 토지를 보다 효과적으로 사용하기 위해 경관 질 및 특성을 평가할 필 요성은 매우 높다고 할 수 있다. 특히 야간경관의 경우, 야간경 관에 대한 인식이나 계획 수요 증가로 야간경관에 관한 연구 필요성을 주지하는 연구들이 증가하고 있음에도 불구하고(Choi et al., 2009; Falchi et al., 2011), 관련 연구들이 부족한 실정이 며, 평가 방식이나 구체적인 가이드라인 제시 부분에서도 미진 한 상황에 머물러 있다. 야간경관평가는 주간경관평가에서 다 루는 경관의 요소, 형태, 색채와 같은 디자인 구성 요소에 대한 영향도 중요하지만, 조명 등 다양한 변인에 의하여 큰 영향을 받을 수 있기 때문에, 보다 고도화된 경관 평가 방법이 접목될 필요성이 제기된다.

이에 본 연구에서는 기존 연구들에서 일반적으로 추진해오 던 시지각적 경관 평가 연구에서 나아가, 보다 객관적이고 합 리적인 기준을 제시하기 위한 야간경관 평가의 기초연구로서 초석을 다지고자 한다. 보다 구체적으로, 야간경관의 특정 평가 대상지나 전체 슬라이드 등 전체 경관 중심의 평가에서 인간의 무의식적인 눈 움직임을 객관적으로 측정할 수 있는 아이트래 
킹 분석 방법 적용을 통하여 경관 요소 중심의 평가를 시도하 고자 한다. 즉, 기존 경관미나 경관 형용사를 대상으로 한 시지 각적 경관 평가방법은 경관의 요소 및 구성에 대한 전체적인 이미지에 대한 해석이 중심이었다면, 아이트래킹을 활용한 경 관 평가방법은 개별적인 경관 요소나 부분 구성에 대한 특성 분석 및 확장된 해석을 가능하게 한다. 예를 들면, 아이트래킹 경관 평가방법을 통한 주요 결과는 경관을 지각함에 있어 피조 사자가 어떤 강도와 시점의 움직임으로 경관 전체 및 요소를 지각하는지, 시선이 많이 고정된 경관 요소와 영역은 어떠한지 를 파악할 수 있다. 또한, 본 연구에서는 기존의 경관 이미지 평 가를 수행하기 위해 일반적으로 활용되는 경관형용사 평가와 의 비교를 동반하여, 아이트래킹 조사 결과와 유사점, 차이점, 보완 가능성을 함께 검증하고자 하였다. 이와 같은 연구 결과 는 기존 시지각적 경관 평가 방법의 확장 가능성을 제시하는 동시에, 주관적인 평가에 치중했던 기존 야간경관 평가 연구의 한계점을 보완해줄 수 있을 것으로 판단된다.

\section{II. 이론적 고찰}

\section{1. 경관 선호 및 평가}

경관은 인간의 시각과 주관에 의해 보여지는 공간의 물리적 형태이다(Kalivoda et al., 2014; Wang et al., 2016). 따라서 경 관은 객관적이고 독립적인 물리적 주체로서 존재하기 보다는 물리적 공간을 인지하는 인간의 개인적, 사회적, 문화적, 환경 적 특성과의 상호작용으로 만들어진다고 볼 수 있다(Surová and Pinto-correia, 2016). 때문에 동일한 물리적 조건을 갖고 있는 공간이라 할지라도, 그것을 바라보는 인간 또는 집단의 특성에 따라 경관은 다르게 만들어질 수 있으며, 이것이 경관 에 대한 개인적 사회적 선호가 다른 이유이기도 하다.

경관은 인간의 삶의 범위 어디에서나 존재하기 때문에 인간 의 삶의 질에 적지 않은 영향을 미친다(Gavrilidis et al, 2016). 따라서 인간 및 사회가 선호되는 형태로 잘 조성되고 관리된 경관은 공익의 가치를 실현할 뿐만 아니라, 궁극적으로는 지역 삶의 질 향상에 기여하게 된다. 따라서 인간에게서 선호되는 경 관의 형태가 어떤 것인지, 또는 특정 사회에서 선호되는 경관 의 형태가 어떤 것인지를 탐색하는 것은 매우 중요한 일이라고 할 수 있다(Surová and Pinto-correia, 2016).

이에 따라 인간 및 사회의 경관 선호에 대한 평가 연구는 다 양한 방법으로 오랫동안 지속되어 왔다(Kuper, 2017). 그 중 가장 기초가 되는 방식은 여러 가지 경관을 사진으로 촬영한 뒤 이에 대한 선호도를 정량적으로 설문하는 방식으로, 설문 참여자가 직접 대상지까지 않아도 된다는 장점과 공간을 인식 함에 있어 시각에 집중할 수 있다는 장점이 있어 널리 사용되 고 있다(Ode et al., 2009).
시각적 선호와 관련된 초기 연구들은 주로 경관의 유형을 문 화경관, 도시경관, 농촌경관, 가로경관 등으로 구분하고, 녹지, 건축물, 도로, 산책로 등 경관을 구성하는 요소들에 대한 선호 도와 전체 경관에 대한 선호도를 정량적으로 설문하여, 선호되 는 경관과 이를 구성하는 경관 요소를 분석하는 내용이 주를 이루었다(Kim, 2001; Ahn et al., 2005). 또한, 전체 경관에 대 한 경관 선호도를 설문하고, 각 경관의 요소가 차지하는 비중 과 패턴을 분석하여, 경관 선호와 경관 요소 구성 간의 관계를 분석하는 연구도 축적되어왔다(Song and Yoon, 2006; Choi and Choi, 2008).

이후 경관에 대한 이미지를 형용사로 평가하는 기법이 개발 되면서, 어떠한 경관 유형 및 경관 요소가 어떤 이미지를 갖는 지, 또는 경관의 이미지가 경관 선호도에 어떠한 영향을 미치 는지 등에 대한 연구도 시도되어왔다(Choi and Choi, 2008; Kim et al., 2012; Yeo et al., 2012; Kim and Choi 2014; Qi et al., 2017). 나아가, 그래픽 기술의 발달에 따라 사진으로 촬영된 경관에, 일부 경관 요소를 변화시키는 시뮬레이션을 시도함으로 써, 부분적인 요인에 대한 가상적인 경관 평가도 가능하게 되 었다(Suh and Choi, 2012; van Zanten et al., 2016; Kuper, 2017).

이러한 연구들은 인간의 주관에 의해 선호되는 경관 특성 및 경관 요소를 정량적으로 분석하였다는데 의의가 있으며, 특히 경관형용사 연구가 더해짐으로써 복잡한, 차가운, 깨끗한 등과 같이 경관 미만으로 설명할 수 없는 다양한 특성을 이해하게 하 고, 경관을 선호하게 되는 배경에 대한 단초를 제공했다는 것 에 의의가 있다.

그러나 경관평가의 결과는 정책 및 과학 분야에서 보편적으 로 해석 가능해야 하기 때문에(Tagliafierro et al., 2016), 객관 적인 평가 방법이 시도됨으로써 다양한 연구 결과의 축적 및 교차 비교를 통해 실무에 타당하게 반영되어야 할 필요성이 제 기된다.

\section{2. 야간경관계획 관련 연구}

경관계획에 관한 대부분의 연구는 주로 야간(夜間) 위주보 다는 주간(書間)경관을 대상으로 집중하여 연구되었으며, 야 간경관 관련 기존연구들의 범주는 주로 야간 조명(Lee et al., 2004; Park et al., 2009; Kong and Kim, 2010; Falchi et al., 2011)과 관련된 연구가 주를 이루어왔다. 이와 같은 야간경관 에 관한 연구들은 아름다운 경관 연출 목표 이상으로 안전성 향상, 빛공해 저감, 범죄예방 설계(CPTED) 등 다양한 목적을 부가적으로 두는 것이 특징적이다. 거시적 관점에서 야간경관 계획에 관한 연구들은 형용사 평가를 통하여 야간경관의 특징 을 조사하거나(Ahn et al., 2007), 야간경관계획 시 필요한 평 가 항목 선정 및 가중치 분석에 초점을 맞추어 연구(Choi et 
al., 2009)를 진행하였다. 또한, Qin et al.(2011)의 연구에서는 야간시간의 관광 활성화를 위하여 야간경관계획이 중요하다 는 논리로 야간경관계획을 진행하기 위한 기초적 야간경관 축, 야간경관 거점, 야간경관 핵심 지역, 권역을 제시한 바 있다. 야 간경관을 주제로 한 환경심리 연구의 대표적 사례로 Fisher and $\operatorname{Nasar}$ (1992)에서는 야간 행동에 영향을 미치는 두려움(fear), 범죄 문제에 초점을 두고 연구를 진행하였다. 해당 연구에서는 특히, 인간 환경 선호(Human environmental preference)와 관 련된 조망 은신 이론(Prospect-Refuge Theory)에 근거하여 야 간시간 내 다른 외부 공간 디자인이 안전 지각(Perception of safety)에 어떤 영향을 미치는지 분석하였다. 또한, Ngesan and Karim(2012)은 야간시간의 공원 이용 고객, 행동, 행동 패 턴 및 맵핑을 도출함으로써, 공원의 다른 물리적 세팅에 따라 이용 고객 연령과 행동 패턴이 다르다는 것을 밝혀냈다. 이를 통해, 향후 공원 설계에 야간 이용을 위한 행동 분석이 반영되 어야 한다는 점을 주장한 바 있다.

이처럼 기존 연구들이 공공공간의 야간 이용을 고려하여 야 간경관계획이 반드시 필요하다는 점은 공통적으로 동의하고 있 으나, 설계에 제안할 수 있는 구체적 해법 제시는 미진하였다. 또한, 다양한 유형의 야간경관을 제시하여 야간경관 이미지에 대한 지각(perception)을 분석하거나 야간시간의 행태 패턴을 통한 가이드라인 연구는 극히 제한적임을 파악할 수 있었다. 따라서 야간경관의 다양한 유형별 이미지 지각 및 분석을 통해 계획 기법에 시사점을 제시할 수 있는 연구가 필요한 시점이다.

\section{3. 아이트래킹 연구}

시선추적기법이라고도 불리는 아이트래킹은 인간의 눈동자 움직임을 지속적으로 관찰하여 자극에 대한 인간의 반응과 정 보 습득 결과를 연구하는 방법으로, 시각적으로 인지하는 인간 들이 어떤 대상에 시각적 주의를 기울이고 있는지 직접적으로 측정한다(Suh et al., 2015). Dupont et al.(2014)의 연구에서는 이러한 아이트래킹 분석방법이 기존의 전통적인 경관 평가 연 구 방식과 다르게 이미지에 의한 경관을 객관적으로 평가할 수 있는 강력한 도구가 될 수 있다고 주장한 바 있다. 아이트래킹 분석 방법은 주로 마케팅 연구나, $\mathrm{HCI}$ 분야의 연구에서 집중적 으로 수행되어 왔으며(Rozado et al., 2015; Fogelton and Benesova, 2016; Kim, 2017), 경관 분야에서는 초기 발전 단계에 해 당한다고 할 수 있다.

경관 연구에서 아이트래킹 분석을 적용한 연구들은 다양한 경관 이미지를 평가 대상으로 설정하여 경관의 특성을 객관적 으로 분석하거나 집단 간 경관 지각의 차이를 검증함으로써 경 관의 폭넓은 이해를 도모하고 있다. Li et al.(2016)의 연구에 서는 주요 관광지에서 촬영한 다양한 경관 이미지를 대상으로 피조사자들이 텍스트를 포함한 경관 요소에 시선을 고정시키
는 경향성이 있음을 파악하였으며, Kang and $\operatorname{Kim}(2015)$ 은 인 간이 무의식적으로 관심을 갖는 영역을 해석하기 위하여, 경관 선호도, 두려움 등의 경관 속성과 비교하는 연구를 시도하였다. 아이트래킹 연구 방법이 인간의 회복지각력을 측정할 수 있는 지를 파악하기 위한 연구도 시도되었는데(Berto et al., 2008), 해당 연구에서는 피조사자가 자연경관을 지각하는 응시(fixation) 시간과 회복지각 간의 부적(-)인 상관관계가 있음을 입 증하였다. 인간이 경관을 지각하는 영역과 방식은 전문가와 비 전문가 간 차이가 있을 것이라는 가설에 입각하여, Dupont et al.(2015)은 일반인들이 전문가들이 지각하는 것보다 한정된 수의 경관 요소에 한정되어 경관을 지각하는 것을 밝혀내었 다. 이는 조경, 경관 관련 전문 지식이 사람들로 하여금 경관을 보는 방법에 영향을 미친다는 것을 보여주는 의미 있는 연구 결과로 판단된다.

이처럼 관련 연구들은 인간의 시선이 고정되는 관심영역 (AOIs) 분석에 집중해왔다. 혹은 경관 이미지별 정량화할 수 있는 응시 시간(fixation duration)이나 횟수(fixation count)와 경관 이미지의 연관성을 파악하는 연구도 지속적으로 시도되 고 있다. 하지만 인간의 시선이 고정되는 관심영역(AOIs)은 단 지 분석 자체에 초점에 두고, 왜 그 영역에 집중하게 되었는지, 무엇을 의미하는지 등의 해석에 대한 심층적인 연구는 제한되 어 나타나고 있다. 또한, 다양한 아이트래킹 분석 변수들과 기 존 연구 방법에서 사용된 변수, 속성들과의 비교를 통하여 향 후 활용방안을 제시한 연구는 매우 부족하다고 할 수 있다.

\section{III. 연구의 범위 및 방법}

\section{1. 연구 가설}

본 연구는 야간경관을 대상으로 한 아이트래킹 분석 방법과 경관 형용사 평가 결과의 비교를 통하여 야간경관을 대상으로 한 경관 평가 방법의 확장을 제안하는 연구로서 아래와 같은 연구 가설을 중심으로 연구를 수행하였다.

첫째, 야간경관을 대상으로 한 아이트래킹 평가 변수와 형용 사 평가 변수 간 상관관계가 있을 것이다.

둘째, 캠퍼스 야간경관을 대상으로 피조사자들의 주목도가 집중적으로 나타난 관심영역(AOIs) 및 경관 요소는 차이가 있 을 것이다.

셋째, 캠퍼스 야간경관의 유형, 요소, 구성에 따라 시선이 이 동하는 특성은 차이가 있을 것이다.

\section{2. 실험 과정}

본 연구는 다양한 야간경관에 대한 일반인들의 시지각을 아 이트래킹 평가 방법과 형용사 평가 기법을 동반하여 평가-비 
교하는 연구로서, 세부적인 연구의 과정은 다음과 같다.

첫째, 연구자는 학교 홈페이지 공고를 통하여 모집된 32명의 다국적 피조사자에게 실험 수행 전, 연구에 대한 목적과 실험 절차에 대한 내용 및 준수 사항을 전달하였다. 연구 수행 전, 연 구자는 연구 수행 및 과정에 대한 자료를 학교의 $\mathrm{IRB}$ (임상연 구윤리위원회)에 제출 - 승인을 받아 연구를 진행하였다.

둘째, 총 32 명의 피조사자들은 약속된 시간에 맞추어 개별적 으로 버지니아공과 주립대학교 시각 예술 지각 및 유용성 실 험실을 방문하였으며, 3 가지 유형의 총 18 개의 다양한 야간경 관에 대한 아이트래킹 및 경관 형용사 설문조사를 약 45 분간 수행하였다. 아이트래킹 수행 전, 피조사자들의 눈을 카메라에 알맞게 고정시키기 위한 측정(Calibration) 작업이 수행되었다. 눈 측정 작업은 피조사자가 스크린 중심에 위치한 빨간 점이 이동하는 방향을 따라가는 방식으로 진행되었으며, 측정 결과 가 정상 범주를 벗어난 결과를 보인 피조사자는 본 실험에서 제외하였다.

본 실험을 진행하기 앞서, 연구자는 평가 모니터, 모니터 상 부의 카메라, 모니터 하부의 적외선 감지기 앞에 피조사자의 위치와 각도와 정확한지 확인하였으며, 실험 동안 움직임을 최 소화할 것을 안내하였다. 야간경관을 평가하는 실험의 특성상, 실험실 전등을 소등하여, 야간경관과 유사한 환경 조성이 되도 록 하였다. 평가 대상 18 가지 야간경관 평가 전, 3 개의 다른 경 관 이미지를 응시하게 함으로써, 실험에 대한 정확도와 신뢰도 를 높이고자 하였다.

본 실험에서는 야간경관을 자연스럽게 8초 동안 응시하는 작 업과 야간경관 응시 후, 야간경관에 대한 형용사 평가를 수행 하는 2가지 유형으로 구분하였다. 아이트래킹 평가는 한 슬라 이드에 한 이미지를 평가할 수 있도록 구성되었으며, 연구자는 피조사자가 야간경관을 자연스럽게 응시할 수 있도록 유도하였 다. 또한 연구자는 8초 간의 야간경관 응시 후, 자동적으로 모 니터에서 설문평가가 수행되게 설계하였으며, 경관 형용사 평 가는 7점 척도로 총 9 개 유형의 문항을 응답하게 하였다.

본 조사 후, 연구자는 마지막으로 피조사자들에게 연령, 성 별, 전공 등 기본적인 인구통계학적 응답을 수행하도록 요청하 였다.

\section{3. 실험 이미지}

조사대상지는 미국 버지니아텍(Virginia Polytechnic Institute and State University) 캠퍼스 내부로 한정하였으며, 조사대상 지 선정 과정 및 이미지 촬영 조건은 다음과 같다. 첫째, 인도 를 중심으로 사람들의 통행량이 많은 곳을 선정하였다. 둘째, 가로등의 조도가 동일한 곳을 선정하여, 빛 세기로 인해 이미 지 지각 정도가 바뀔 수 있는 것을 통제하고자 하였다. 셋째, 동일한 시간 및 동일한 계절에 촬영하는 것을 기준으로 하였
으며, 이에 오후 8시에서 9시 사이 늦여름(9월초)에 촬영하였 다. 넷째, 본 연구에서는 캠퍼스 내 야간경관을 대상으로 하는 연구의 특수성으로 기존 연구들을 참고하는 동시에, 미리 촬영 한 야간경관 사진을 토대로 전문가 평가를 실시하여 공간의 전 체 구조는 유사하나, 경관요소가 다른 대상지가 포함되게 선정 하였다. Figure 1의 예시 사진처럼, 일부 경관은 건물 중심의 경관, 또 다른 예시는 건물을 배경으로 나무나 초화류가 지배 적인 구성을 나타내고 있다.

상기의 제시한 이미지 설정 네 가지 기준을 기본틀로 설정하 고, 총 50 개의 사진 촬영을 실시하였으며, 이 중 전문가 3 인(조 경, 건축 분야 10 년 이상의 경력의 교수 및 박사)의 검토 과정 을 통하여 중복되거나 경관의 형태를 파악하기 힘든 이미지는 제외하였다.

\section{4. 아이트래킹 장비}

아이트래킹은 시선의 지점(“우리가 어느 곳을 보고 있는지”) 또는 머리에 대한 눈의 상대적인 움직임을 측정하는 과정이다 (Wikipedia). 본 연구에서는 눈의 위치를 비디오 이미지 방법 으로 전달하는 하드웨어(SMI)와 분석 소프트웨어(BeGaze)를 사용하였다. 시선을 추적하는 방식에는 코일 이용, 빛의 반사 등 다양한 평가 방법이 있는데, 본 연구에서는 카메라로부터 방출된 적외선이 특정한 각도로 조사되어 동공의 중심 위치를 계산하는 방식인 Dark Pupil System 방식을 활용하였다. 실험 환경은 아이트래킹 분석 소프트웨어가 설치된 한 대의 컴퓨터 와 실제 눈의 움직임을 측정하는 기구가 장착된 다른 한 대의 컴퓨터가 설치된 실험실이었다. 아이트래킹 장비가 장착된 메 인컴퓨터는 모니터 위에 카메라, 모니터 아래에 적외선 감지 시스템이 부착되어 있는 구성이다.

\section{5. 피조사자}

홈페이지를 통하여 모집된 피조사자는 35명으로, 본 실험 전 측정(Calibration) 과정을 통해 실험평가에 적절하지 않은 조사 자는 제외하고 총 32 명이 최종 피조사자로 선정되었다. 32 명은 일반적인 설문평가의 적절한 표본수로 인식하기 어려우나, 인

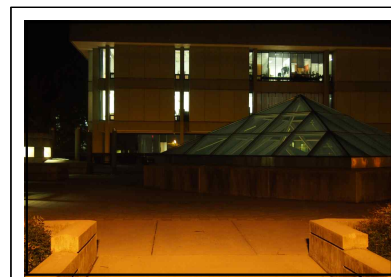

a: Sample 1

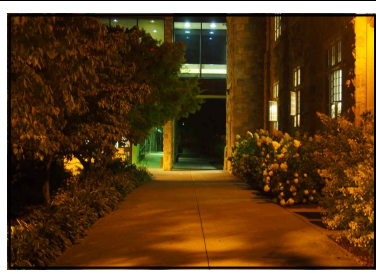

b: Sample 2
Figure 1. The examples of photograph stimuli 


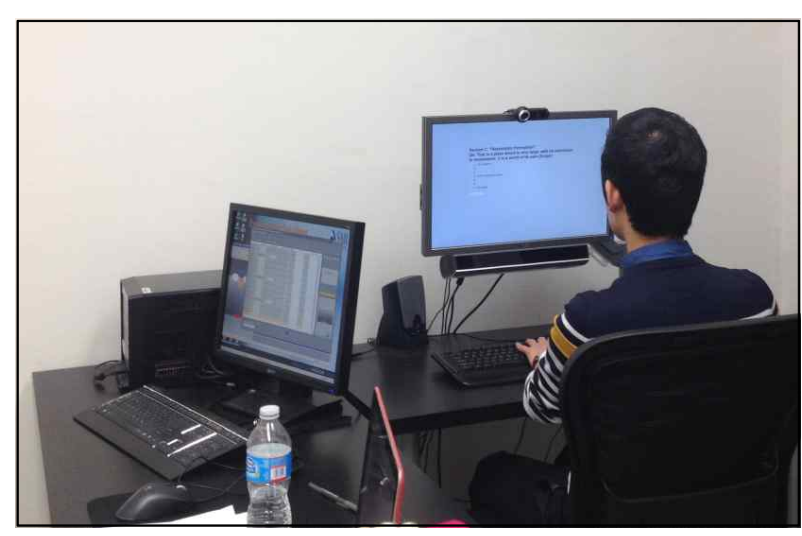

Figure 2. Experimental environment

체의 실험을 동반하는 아이트래킹 조사의 경우, 상대적으로 적 은 표본수를 요구하는 것이 일반적이고, $\operatorname{Kim}(2016)$ 에서는 아 이트래킹 연구에서 대개 5 10명의 참여자를 대상으로 실시하 는 것이 보편적이라고 제시한 바 있다. 피조사자는 20 대에서 40 대의 연령대로 구성되었으며, 아시안, 미국인, 중동인 등 다 양한 국적을 가진 학생 혹은 연구원이었다. 피조사자의 남녀 비율은 53:47로 성별로 인한 연구 결과의 차이를 최소화하고자 하였다. 본 실험 수행 전 피조사자들에게 $\mathrm{IRB}$ (임상연구윤리위 원회)에 제출·승인 받은 실험에 대한 개요에 대하여 충분히 인지시키고, 피조사자별 서명을 받은 후 Figure 2와 같이 개별 적으로 실험을 진행하였다.

\section{6. 변수}

\section{1) 아이트래킹 변수}

아이트래킹 수행 연구에서 가장 흔하게 활용되는 응시(fixaon) 변수는 단순히 눈이 이동하는 것을 의미하는 것이 아니라, 일정 시간 이상 시선이 고정되어 있는 것을 전제로 한다. 즉, 사 람이 어느 물체나 경관에 대하여 일정 시간 '응시'한 것은 관심 있게 그 대상을 본 것으로 인식하기 때문에, 많은 연구에서 의 미 있는 변수로 활용되어 왔다. 국내외 연구를 막론하고 0.1 초 이상 $1^{\circ}$ 이내에 눈길이 머물러 있는 것을 응시라고 정의하는 경우가 많다 $(\mathrm{Kim}, 2017)$. 눈 깜빡임 수는 문자 그대로 일정 물 체를 보는 동안 발생한 총 눈 깜빡임 수를 의미하고, 기존 연구 들에서는 눈 깜빡임의 사람들의 집중력을 판단하는 잣대로 활 용하거나 해당 알고리즘을 개발하는 방식의 기술적인 연구가 수행되어 왔다(Slagter, 2015; Fogelton and Benesova, 2016). 시선의 이동 길이는 대상을 보는 동안 발생하는 시선의 길이를 의미하며, 기존의 관련 연구(Kim et al., 2013; Kang and Kim, 2015)에서는 경관 유형 및 요소별 응시 강도의 차이를 확인하 기 위한 변수로 활용해왔다. 본 연구에서는 시선의 이동 길이 에 대한 수치 비교뿐만 아니라, 이미지별 응시 강도 및 위치
Table 1. Eye tracking measurements

\begin{tabular}{c|l|c}
\hline Measurement & \multicolumn{1}{|c|}{ Meaning } & Previous studies \\
\hline $\begin{array}{c}\text { Fixation duration } \\
\text { (응시 시간) }\end{array}$ & $\begin{array}{l}\text { Duration of all fixations } \\
\text { (no eye movement) }\end{array}$ & $\begin{array}{c}\text { Berto et al.(2008) } \\
\text { Kang and Kim(2015) }\end{array}$ \\
\hline $\begin{array}{c}\text { Blink count } \\
\text { (눈깜빡임 수) }\end{array}$ & Number of blinks & $\begin{array}{c}\text { Fogelton and } \\
\text { Benesova(2016) } \\
\text { Zhang et al.(2017) }\end{array}$ \\
\hline $\begin{array}{c}\text { Scan path length } \\
\text { (시선 이동 길이) }\end{array}$ & $\begin{array}{l}\text { The length of gaze positions } \\
\text { and eye movements plotted } \\
\text { on the stimulus image }\end{array}$ & $\begin{array}{c}\text { Kim et al.(2013) } \\
\text { Kang and Kim(2015) }\end{array}$ \\
\hline $\begin{array}{c}\text { Saccade duration } \\
\text { (시선의 급격한 } \\
\text { 이동 시간) }\end{array}$ & $\begin{array}{l}\text { Duration of quick eye move- } \\
\text { ments as the gaze travels } \\
\text { from one fixation point to } \\
\text { another }\end{array}$ & Kim et al.(2013) \\
\hline
\end{tabular}

Definitions follow SensoMotoric Instruments(2012). AOIs=Area of Interest

를 보여주는 Heat map을 제시하였다. Heat map은 응시 지역 (fixation areas)이 표시된 시선의 위치 및 강약을 보여주며, 본 연구에서는 응시 지역 간 응시 강도 비교를 위하여 활용하였다. Heat map에서 표시된 응시 지역의 강도를 확인을 위한 방법은 색상으로서, 초록 $\rightarrow$ 노랑 $\rightarrow$ 빨강의 순으로 응시 강도가 높아 지는 것으로 해석할 수 있다. 시선의 급격한 이동 시간(Saccade duration)은 자극의 한 지점에서 다른 지점으로 시선을 이동할 때 발생하는 급격한 이동으로서, 응시(fixation)와 응시 (fixation) 사이 발생하는 시선의 도약으로 설명할 수 있다(SM, 2012). 이와 같이 연구 실험에 쓰인 아이트래킹 변수에 대한 자 세한 설명 및 참고 문헌은 Table 1 과 같다.

\section{2) 형용사 평가 변수}

본 연구의 다양한 야간경관을 평가하기 위한 경관 형용사 설 정의 기준으로서 첫째, 기존 연구에서 활용된 변수 설정과 둘 째, 야간경관이라는 특수성을 반영하여 전문가 3 인(조경, 건축 분야 10 년 이상의 경력의 교수 및 박사)의 검토를 반영하였다. 특히 기존 연구에서 활용한 경관 형용사 변수는 야간경관을 대 상으로 평가한 연구만을 대상으로 하여, 야간경관 평가의 특수 성에 부합하는 형용사 변수를 설정하고자 하였다. 최종 선정된 9 개의 변수 및 선정 기준은 Table 2 와 같다.

\section{7. 통계 분석}

통계 분석은 연구의 가설에서 설정한 내용들을 객관적으로 증명하기 위하여 활용하였다. 야간경관 이미지에 대한 경관 형 용사 변수와 아이트래킹 변수 간 연관성을 밝히기 위한 통계 분석은 상관분석(Pearson's correlation)을 활용하였다. 이와 같 은 통계 분석은 모두 Excel을 통한 코딩 및 SPSS ver. 16을 통 한 결과 분석을 활용하여 이루어졌다. 
Table 2. Selection of adjectives for landscape assessment

\begin{tabular}{c|c}
\hline Type & Basis \\
\hline $\begin{array}{c}\text { Very unpleasing-Very pleasing } \\
\text { (추한 - 아름다운) }\end{array}$ & $\begin{array}{c}\text { Ahn et al.(2007), Kang and } \\
\text { Kim(2015), Kim et al.(2013), } \\
\text { Yoon and Chung(2012) }\end{array}$ \\
\hline $\begin{array}{c}\text { Very boring - Very interesting } \\
\text { (지루한 - 흥미로운) }\end{array}$ & $\begin{array}{c}\text { Ahn et al.(2007), } \\
\text { Yoon and Chung(2012) }\end{array}$ \\
\hline $\begin{array}{c}\text { Very simple - Very complicating } \\
\text { (단순한 - 복잡한) }\end{array}$ & Ahn et al.(2007), \\
\hline $\begin{array}{c}\text { Very fearful - Very safe } \\
\text { (두려운 - 안전한) }\end{array}$ & $\begin{array}{c}\text { Kang and Kim(2015), } \\
\text { Yoon and Chung(2012) }\end{array}$ \\
\hline $\begin{array}{c}\text { Very cold - Very warm } \\
\text { (차가운 - 따뜻한) }\end{array}$ & $\begin{array}{c}\text { Ahn } \text { et al.(2007), } \\
\text { Yoon and Chung(2012) }\end{array}$ \\
\hline $\begin{array}{c}\text { Very unclear - Very clear } \\
\text { (희미한 - 선명한) }\end{array}$ & $\begin{array}{c}\text { Ahn et al.(2007), Kang and } \\
\text { Kim(2015), } \\
\text { Yoon and Chung(2012) }\end{array}$ \\
\hline $\begin{array}{c}\text { Very unharmonious - Very harmonious } \\
\text { (조화롭지 않은 - 조화로운) }\end{array}$ & Ahn et al.(2007), \\
\hline $\begin{array}{c}\text { Very inaccessible - Very accessible } \\
\text { (접근성이 낮은 - 접근성이 높은) }\end{array}$ & Expert elicitation \\
\hline $\begin{array}{c}\text { Very unsatisfying - Very satisfying } \\
\text { (만족하지 않는 - 만족하는) }\end{array}$ & Expert elicitation \\
\hline
\end{tabular}

\section{IV. 연구의 결과}

\section{1. 아이트래킹 분석 결과}

32 명의 다국적 피조사를 대상으로 이미지별 아이트래킹 분석 을 수행한 결과는 Table 3과 같다. 눈 깜박임 수의 평균 3.1회, 응시 시간 평균 $199 \mathrm{~ms}$, 시선의 이동 길이 $6,554.5 \mathrm{px}$, 시선의 급

Table 3. The results of eye tracking analysis

\begin{tabular}{c|c|c|c|c}
\hline $\mathrm{N}$ & $\begin{array}{c}\text { Blink } \\
\text { count } \\
(\mathrm{N})\end{array}$ & $\begin{array}{c}\text { Fixation } \\
\text { duration } \\
\text { average } \\
(\mathrm{ms})\end{array}$ & $\begin{array}{c}\text { Scan path } \\
\text { length } \\
(\mathrm{px})\end{array}$ & $\begin{array}{c}\text { Saccade } \\
\text { duration } \\
\text { average } \\
(\mathrm{ms})\end{array}$ \\
\hline 1 & 3.0 & 179.1 & $6,171.4$ & 66.3 \\
\hline 2 & 3.6 & 191.0 & $6,529.6$ & 58.5 \\
\hline 3 & 3.4 & 191.9 & $6,819.2$ & 57.6 \\
\hline 4 & 3.4 & 189.9 & $6,671.4$ & 58.7 \\
\hline 5 & 3.4 & 189.9 & $6,351.6$ & 58.7 \\
\hline 6 & 3.4 & 191.5 & $6,384.6$ & 59.6 \\
\hline 7 & 3.4 & 198.9 & $7,258.4$ & 62.3 \\
\hline 8 & 2.6 & 202.9 & $6,124.6$ & 55.4 \\
\hline 9 & 3.2 & 204.8 & $6,023.8$ & 48.4 \\
\hline 10 & 2.8 & 216.6 & $5,464.0$ & 45.2 \\
\hline 11 & 2.6 & 212.2 & $6,962.4$ & 41.6 \\
\hline 12 & 2.8 & 219.0 & $7,893.0$ & 43.5 \\
\hline Average & 3.1 & 199.0 & $6,554.5$ & 54.7 \\
\hline SD & 0.4 & 12.3 & 633.2 & 8.0 \\
\hline
\end{tabular}

격한 이동시간 평균은 $54.7 \mathrm{~ms}$ 로 나타났다. 특히 12 개의 야간경 관 중 응시 시간이 가장 높았던 경관은 12 번째 야간경관(i)으 로서(Figure 5), 양쪽 가로변으로 관목류와 초화류가 식재된 공간의 특성을 지니고 있었다.

\section{2. 아이트래킹 변수와 경관 형용사 변수 결과 간 연 관성}

아이트래킹 결과가 의미하는 경관 요소의 시지각적 특성을 보다 정확히 파악하고, 형용사 평가 방법과 보완할 수 있는 방 안 마련을 위해 상호 변수 간 상관분석(Pearson's correlation) 을 수행하였으며, 유의한 상관관계를 지니는 변수들만 추려놓 은 결과는 Table 4 와 같다.

우선, 눈 응시 시간과 “아름다운”, “흥미로운”, “접근성이 높 은”, “만족하는”간 정적 $(+)$ 인 상관관계가 유의미한 것으로 도 출되었다. 이는 이미지 지각 시, 아름답고, 흥미로우며, 접근성 을 높게 인지시키는 요소가 지배적일수록 응시 시간이 더 높은 것으로 해석된다. 시선 이동 길이는 “안전한”, “만족하는”의 형 용사 평가 결과와 정적으로 높은 상관성을 나타냈으며, 이는 조사 이미지 내 요소를 더 안전하게 인지하고, 만족하는 정도 가 높을수록 이미지 내 이동하는 시선의 추적 길이가 더 길다 는 것이라고 판단할 수 있다. 마지막으로 시선의 급격한 이동 시간은 오히려 “아름다운”, “조화로운”, “접근성이 높은”, "만 족하는"과 부적(-)인 상관관계를 지니는 것으로 도출되었다. 즉, 기존 연구(Kang and Kim, 2015)에서 아이트래킹 연구는 전체적인 이미지 지각에 대한 아이트래킹 변수 수치가 결정되 기 보다는 전체 경관 내에 포함된 경관 요소의 특수성이나 면

Table 4. The result of Pearson's correlation between eye tracking measurement and adjective measurement

\begin{tabular}{|c|c|c|c|c|c|c|c|c|}
\hline & \multicolumn{7}{|c|}{ Adjective measurement } \\
\hline & & & a & b & C & d & $\mathrm{e}$ & f \\
\hline \multirow{6}{*}{$\begin{array}{l}\text { Eye } \\
\text { mea- } \\
\text { sure- } \\
\text { ment }\end{array}$} & \multirow{2}{*}{ A } & $R$ & $.643^{4}$ & .633 & .533 & .667 & $.765^{*}$ & .649 \\
\hline & & Sig. & .024. & .027. & .074 & .018 & . 004. & .022. \\
\hline & \multirow{2}{*}{ B } & $\mathrm{R}$ & .511 & .492 & $.635^{\circ}$ & .492 & .406 & .632 \\
\hline & & Sig. & .089 & .104 & .026 & .105 & .190 & .028 \\
\hline & \multirow{2}{*}{ C } & $\mathrm{R}$ & $-.590^{*}$ & -.545 & -.469 & $-.700^{*}$ & $-.663^{*}$ & -.590 \\
\hline & & Sig. & 年. & .067. & 124 & .011 & 019 & .044 \\
\hline
\end{tabular}

a: Very unpleasing-Very pleasing (추한 - 아름다운)

b: Very boring - Very interesting (지루한 - 흥미로운)

c: Very fearful - Very safe (두려운 - 안전한)

$\mathrm{d}$ : Very unharmonious - Very harmonious (조화롭지 않은 - 조화로운)

$\mathrm{e}$ : Very inaccessible - Very accessible (접근성이 낮은 - 접근성이 높은)

$\mathrm{f}$ : Very unsatisfying - Very satisfying (만족하지 않는 - 만족하는)

A: Fixation duration average(ms)

B: Scan path length(px)

C: Saccade duration average $(\mathrm{ms})$

$p<.05$ (음영으로 표시) 
적에 의하여 영향을 받기 때문에, 전체 이미지와 아이트래킹 변수간 관계성보다는 전체 이미지 내 경관 요소와 아이트래킹 변수의 의미를 해석하는 것이 바람직하다.

\section{3. 관심지역(Areas of Interest: A0ls) 분석 및 비교}

피조사자들의 시선이 보다 더 머물렀던 장소를 의미하는 관 심지역(AOIs) 분석은 Figure 3의 Heat map 결과에서 파악할 수 있다. 우선 Kim et al.(2014)의 연구에서 다양한 야간경관을 대상으로 한 실제 경관 평가와 실내 아이트래킹 평가 간 응시 시간 및 관심 지역(AOIs) 차이가 없다는 결과를 제시하였기 때문에, 본 연구의 결과가 실제 경관을 대상으로 한 아이트래 킹 평가 결과와 유사할 것이라는 것을 기대할 수 있다. 분산된
$\mathrm{AOIs}$ 의 영역 지정을 통하여 가장 높은 면적을 차지한 경관 요 소는 '도로'인 것으로 분석됐으나, '도로'에 대한 관심도가 높아 서이기보다는 전체 영역을 인지하는 일반적인 과정에서 나타 난 결과라고 판단된다. Heat map을 통한 $\mathrm{AOIs}$ 영역 분석에서 는 분산된 $\mathrm{AOIs}$ 영역이 나타난 결과보다는 어느 한 두 지점에 집중하여 $\mathrm{AOIS}$ 가 나타난 결과를 주목할 필요가 있다. 12 가지 의 Heat map 분석 결과 중, 일부 지점에 국한되어 관심지역이 나타난 이미지는 $3,4,9,10$ 이미지 $(\mathrm{c}, \mathrm{d}, \mathrm{i}, \mathrm{k})$ 에 해당한다 (Figure 3 참조). 이 중 c, d 2개 이미지의 공통적인 특성은 관 심지역의 영역이 문(door)에 고정되어 나타난 것이다. 한편, Stimuli 9번째인 (i) 이미지는 비스타 경관(일정 방향으로 축선 을 가진 풍경)의 유형으로 소실점이 만나는 지점에서 관심 영 역이 집중된 것으로 나타났으며, Stimuli $11,(\mathrm{k})$ 이미지의 경우

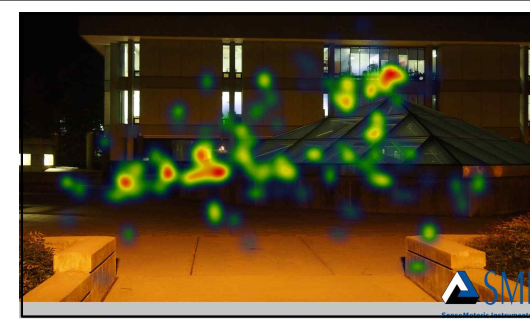

a: Stimuli 1

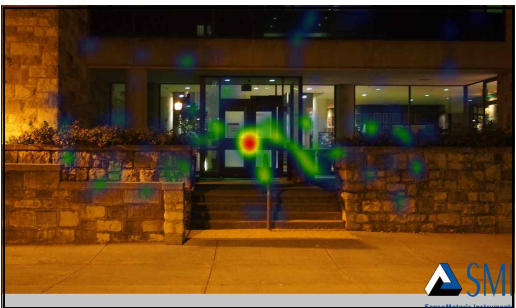

d: Stimuli 4

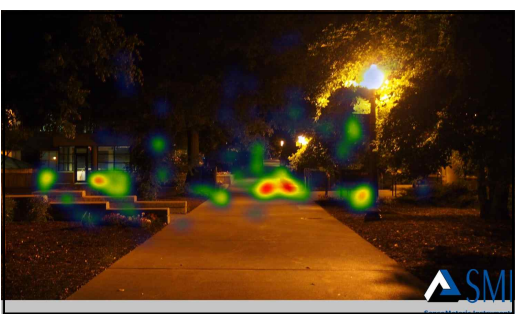

g: Stimuli 7

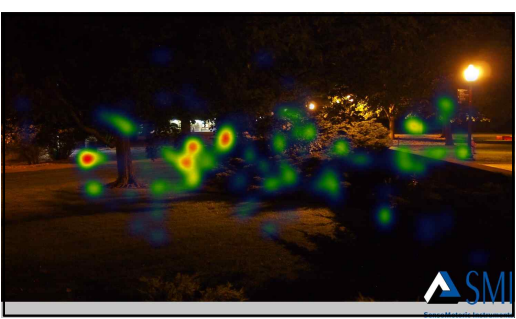

: Stimuli 10

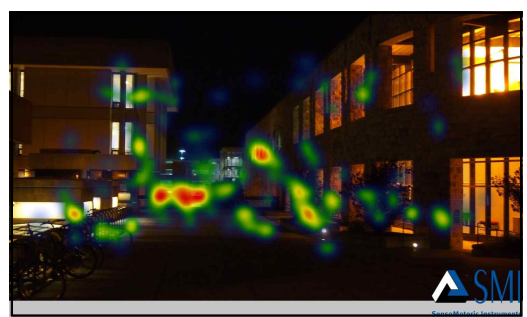

b: Stimuli 2

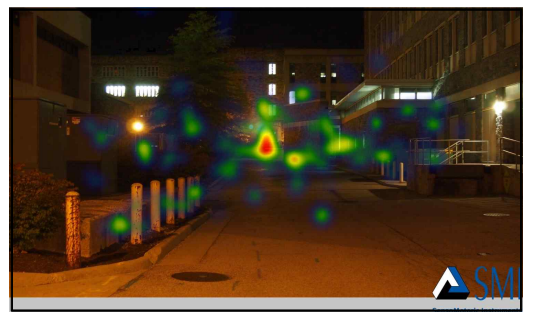

e: Stimuli 5

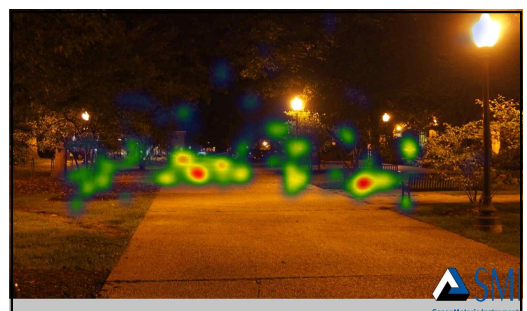

h: Stimuli 8

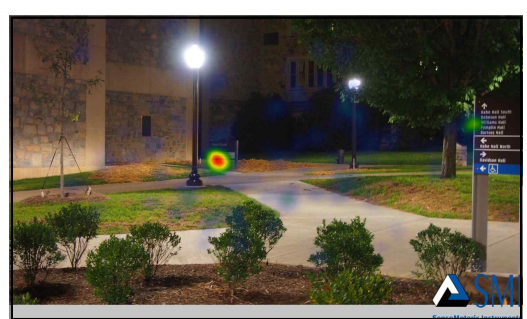

$\mathrm{k}$ : Stimuli 11

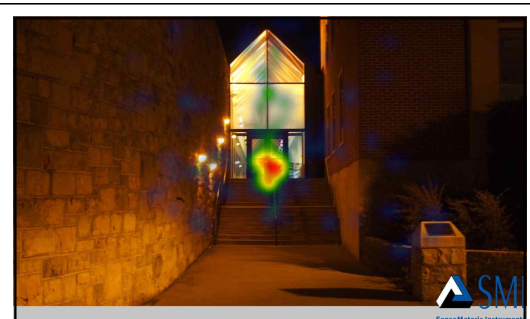

c: Stimuli 3

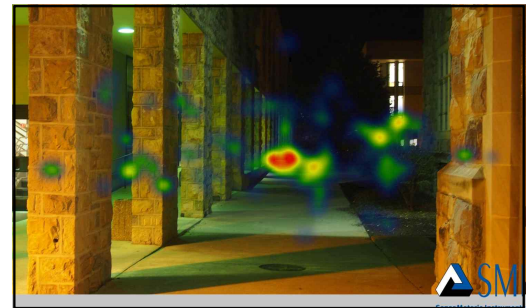

f: Stimuli 6

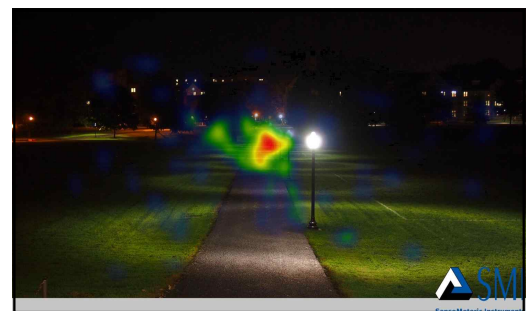

i: Stimuli 9

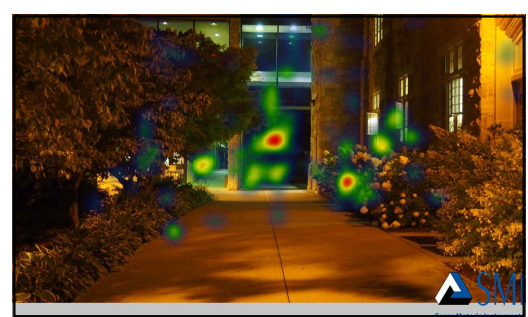

1: Stimuli 12

Figure 3. The results of AOls using Heap map analysis 
는 특정 경관 요소인 '표지판'에 대부분의 시간을 고정하는 것 으로 도출되었다.

\section{V. 논의 및 결론}

본 연구는 다양한 야간경관의 특성을 파악하기 위하여 아이 트래킹 평가 방법과 경관 형용사 평가 방법의 비교를 통하여 시지각적 경관 지각에 대한 이해를 높이고, 경관 평가 영역을 확장하기 위한 연구 논문이다. 32 명의 다국적 피조사자를 대상 으로 아이트래킹 평가 및 경관 형용사 평가를 진행하여 도출된 주요 연구 결과는 다음과 같다.

첫째, 아이트래킹 변수와 형용사 변수 간 연관성 조사는 아 이트래킹 변수의 평가 결과가 의미하는 바를 형용사 평가라는 대리 변수를 통하여 명확히 설명될 수 있는지 파악하고자 수행 되었다. 우선, 눈 응시 시간은 '아름다운, '흥미로운, '접근성이 높은, '만족하는'의 변수와 정적(+)인 상관관계를 지니는 것으 로 도출되었다. 이는 전체 경관 내 경관 요소를 인지함에 있어 '아름답게', ‘흥미롭게', '접근성이 높게', '만족하게' 느낄수록 응 시 시간이 상대적으로 높아지는 것으로 이해할 수 있다. 기존 아이트래킹 연구에서 거의 다루어지지 않은 '흥미로운', '접근 성이 높은, '만족하는'이라는 형용사 변수와 눈 응시 시간 간 정적 상관성은 의미 있는 결과라고 할 수 있다. 한편, 시선 이 동 길이는 '안전한', '만족하는'의 형용사 변수와 정적인 연관관 계를 갖는 것으로 나타났다. 이는 한 경관 이미지 내에서 위치 한 경관 요소들을 안전하고, 만족스럽게 지각할수록 시선의 이 동거리가 더 길어지는 것으로 해석할 수 있다. 시선의 급격한 이동시간은 '아름다운, '조화로운', '접근성이 높은, '만족하는' 이라는 긍정적 의미의 형용사 평가 결과와 상관관계가 반비례 하는 것으로 도출되었다. 즉, 눈 응시 시간과 시선의 급격한 이 동 시간 간 부적(-)인 상관관계가 증명된 것을 미루어보아, 시 선이 고정되고 관심이 가는 영역이 상대적으로 부족할수록 집 중할 대상을 탐색하기 위해 시선의 급격한 이동시간이 높아지 는 경향을 보이는 것으로 판단된다.

둘째, Kang and $\operatorname{Kim}(2015)$ 의 연구에서는 아이트래킹 경관 평가가 기존 경관 이미지 설문지 평가와 달리 경관의 전체적 구성보다는 '경관 요소'에 집중할 필요성을 주지한 바 있다. 다 만, 일부 관심영역 $(\mathrm{AOIs})$ 이 특정 이미지들에 국한되지 않고 분산되어 나타나는 분석 결과는 단지 전체 경관 지각을 위한 과정임을 인지할 필요가 있다. 특정 이미지에 국한되어 나타난 Heat map 분석 결과에서는 '문', '표지판' 등 특수 경관 요소에 집중하여 시선이 고정되는 것으로 도출되었다. 이는 해당 경관 요소가 아름답거나, 안전하거나, 조화로운 느낌을 주기 때문이 라기보다는 '문', '표지판' 등을 통하여 “무엇을 할 수 있고”, "무엇을 읽을 수 있고" 등 향후 행위 가능성에 초점이 맞추어
져 나타난 결과라고 판단된다. 즉, '문', '표지판' 등의 경관 요소 가 향후 행동을 유발하는 장치로서 인식되기 때문에 시선의 고 정을 인도한 것이라고 해석할 수 있다. Li et al.(2016)의 아이 트래킹 연구 결과에서, 중점적으로 지각하는 관심 영역(AOIs) 이 텍스트가 포함된 표지판, 간판, 현수막 등에 집중되어 나타 난 결과는 본 연구에서 도출된 이와 같은 결과를 뒷받침한다. 이는 나아가 기존 경관 선호의 한 이론인 깁슨(Gibson)의 '지 원성(Affordance)'의 개념으로도 설명이 가능하다. 지원성은 물질, 표면, 대상 혹은 기타 생물에 의해 개인에게 제공되는 '행 동의 가능성'을 의미한다(Gibson, 1977). 즉, 지원성은 우리가 지각할 수 있는 특정 환경에서 수행 가능한 '행동'에 의존하는 결과(Chemero, 2003; Raymond et al., 2017)를 대변하며, 이러 한 행동의 가능성은 결국 경관에 대한 선호로 이어진다는 의미 이다. 따라서 향후 경관을 평가하는 아이트래킹 실험 연구에서, 관심영역이 의미하는 바는 단순히 선호하거나 관심을 갖는다 는 의미에서 나아가 확장되어 해석될 필요가 있다. 또한, 의도 적으로 시선 집중(high visual impact)을 꾀하는 랜드마크 설정 시(Dupont et al., 2016), 아이트래킹을 이용한 시선 이동 및 패 턴 결과가 전략적으로 활용될 수 있을 것이다.

이제는 정부가 일방적으로 공간과 경관을 보급하는 시대에 서 경관의 소비자가 적극적인 참여를 통해 경관을 만드는 시대 로 변하고 있다(Kim and Son, 2017). 따라서 사람들이 선호하 고 만족할 수 있는 경관 구성, 요소에 대한 경관 평가 연구가 축적되어야 한다고 판단되며, 기존 연구의 한계를 보완해줄 수 있는 효율적인 연구방법을 찾기 위하여 관심을 가질 필요가 있 다(Woo and Suh, 2017). 특히 아이트래킹을 활용한 경관 평가 방법은 기존의 경관 평가 방법과 다르게 경관 전체에 대한 결 과보다는 개별적인 경관의 요소에 대한 평가가 가능함으로써 다양한 환경에서 어떤 경관 요소, 색채, 구성이 적합할지 혹은 사람들의 시선을 유도해야 할 경관 요소가 어떻게 설정되어야 할지에 대한 해답을 줄 수 있다. 따라서 기존의 경관 평가 방법 을 활용하여 경관의 전체적인 평가를 수행하고, 경관의 개별적 인 요소에 대한 평가 및 계획은 아이트래킹 방법을 활용한 연 구 결과로 보완할 수 있을 것이라고 판단된다. 특히, 아이트래 킹 분석 방법이 기존 경관 선호에 대한 현상을 설명하기 위하 여 개념으로만 제시되었던 경관 선호 이론들을 새로운 방식으 로 뒷받침할 수 있는 가능성을 확인한 부분은 의미있는 결과라 고 판단된다. 다만 많지 않은 피조사자의 샘플 수 및 평가 대상 이미지 수, 다양한 경관 유형을 구분하여 적용하지 못한 점, 아 이트래킹 평가와 경관형용사 평가의 목적 차이를 반영하지 못 한 점 등은 연구의 결과를 일반화시키기 어려운 한계점으로 남 는다. 또한, 연구 설계 시 가로등의 조도가 동일한 지역으로 선 정하여 사진 촬영을 수행하였으나, 가로등과 사진 촬영 장소의 거리 차이에 의하여 발생한 실제 지각 조도 차이에 대한 한계 
점도 후속 연구에서는 보완되어야 할 것이다.

향후 연구에서는 본 연구에서 밝혀내지 못한 연구 과제를 중 심으로 다양한 경관 이미지를 평가하여 구체적인 계획 및 설계 에 시사점을 제시할 계획이며, 인구 특성에 따른 아이트래킹 결과 비교 연구도 동반되어야 할 것으로 판단된다.

\section{References}

1. Ahn, D., J. Son, and M. Kim(2005) Rurality and preferences of rural landscapes in Korea: A comparison of evaluations by Koreans and Foreigners. Journal of Korean Society on Rural Planning 11(3): $43-52$.

2. Ahn, H., Y. Choi, I. Jeong, and J. Kim(2007) A evaluation of the subjective response on image of night streetscape. Journal of the Korean Institute of Illuminating and Electrical Installation Engineers 21(3) : 1-10.

3. Berto, R., S. Massaccesi and M. Pasini(2008) Do eye movement measured across high and low fascination photograph? Addressing Kaplan's Fascination Hypothesis 28(2): 185-191.

4. Chemero, A. (2003) An outline of a theory of affordance. Ecological Psychology 15: 181-195.

5. Choi, M., and J. Choi(2008) A study on the improvement of streetscape through analysis of visual and perceptual characteristics of the urban streetscape in Taegu in Korea and Munich in Germany. Journal of Architectural Institute of Korea: Planning 24(1): 37-44.

6. Choi, M., J. Ro, and J. Koo(2009) A study on the selection of the evaluation criteria and their weights of nightscape plannings. Urban Design 10(3) : 107-122.

7. Council of Europe(2000) The European Landscape Convention. Strasbourg (Accessed 5 November 2015).

8. Dramstad, W. E., M. S. Tveit, W. J. Fjellstad and G. L. A. Fry (2006) Relationship between visual landscape preference and mapbased indicators of landscape structure. Landscape and Urban Planning 78 (4) : 465-474.

9. Dupont, L., M. Antrop and V. Van Eetvelde(2014) Eye-tracking analysis in landscape perception research: Influence of photograph properties and landscape characteristics. Landscape Research 39(4): 417-432.

10. Dupont, L., M. Antrop and V. Van Eetvelde(2015) Does landscape related expertise influence the visual perception of landscape photograph? Implications for participatory landscape planning and management. Landscape and Urban Planning 143: 68-77.

11. Dupont, L., M. Antrop and V. Van Eetvelde(2016) Comparing saliency maps and eye-tracking focus maps: The potential use in visual impact assessment based on landscape photographs. Landscape and Urban Planning 148: 17-26.

12. Falchi, F., P. Cinzano, C. D. Elvidge, D. M. Keith, and A. Haim (2011) Limiting the impact of light pollution on human health, environment and stellar visibility. Journal of Environmental Management 92: 2714-2722.

13. Fisher, B., and J. L. Nasar(1992) Fear of crime in relation to three exterior site features: Prospect, refuge and escape. Environment and Behavior 24: 35-65.

14. Fogelton, A. and W. Benesova(2016) Eye blink detection based on motion vectors analysis. Computer Vision and Image Understanding 148: 23-33.

15. Gavrilidis, A. A., C. M. Ciocanea, M. R. Nita, D. A. Onose and I. I.
Nastase(2016) Urban landscape quality index: Planning tool for evaluating urban landscapes and improving the quality of life. Procedia Environmental Sciences 32: 155-167.

16. Gibson, J. J.(1977) The Theory of Affordances. In R. Shaw \& J. Bransford (Eds.), Hillsdale, NJ: Erlbaum.

17. Im, S.(1991) The Theory of Landscape Analysis. Seoul: Seoul National University Press.

18. Im, S.(2008) The Theory of Urban Landscape Planning. Seoul: Jipmoondang.

19. Kalivoda, O., J. Vojar, Z. Skrivanova and D. Zahradník(2014) Consensus in landscape preference judgments: The effects of landscape visual aesthetic quality and respondents' characteristics. Journal of Environmental Management 137: 36-44.

20. Kang, Y., and M. Kim(2015) Application strategies of eye-tracking method in nightscape evaluation. Journal of the Korean Institute of Landscape Architecture 43(4): 87-97.

21. Kim, T.(2006) A study on the instinctive gaze movement for scattered stimuli. Korean Society of Basic Design \& Art 7(1): 79-87.

22. Kim, D., S. W. Kim and M. R. Kim(2012) A study on the image characteristics of visual perception in Bukchon-streetscape: Focusing on the Samchung-dong 35, Gahoe-dong 31, Gahoe-dong 11. Journal of Korean Institute of Traditional Landscape Architecture 30(2): 110-118.

23. Kim, D. and W. Y. Choi(2014) A study of landscape images and elements of landscape formation on traditional old houses: Focusing on Seongyojang. Journal of Korean Society of Design Culture 20(1): 105-115.

24. Kim, G. (2017) Visual understanding of advertising through eyetracking methodology. Korean Association for Advertising and Publio Relations 19(2): 41-84.

25. Kim, J.(2001) A study on analysis of preference of streetscape. Journal of Korea Planning Association 36(6): 251-257.

26. Kim, M., Y. Kang and S. Abu Bakar(2013) A nightscape preference study using eye movement analysis. ALAM CIPTA 6(2): 85-99.

27. Kim, M, Y. Kang, S. Hong and T. Abel(2014) Difference of perceived fear between actual environment and image-based environment using eye-tracking method. Proceeding in Digital Landscape Architecture. pp. 331-340.

28. Kim, T. Y.(2006) A study on the instinctive gaze movement for scattered stimuli. Korean Society of Basic Design \& Art 7(1): 79-87.

29. Kim, Y., and Y. Son(2017) Difference of place identity perception and landscape preference between residents and tourists in Ihwadong mural village. Journal of the Korean Institute of Landscape Architecture 45(1): 105-116.

30. Kong, H. and J. Kim(2010) Light pollution of outdoor lighting in coastal area: Focused on Busan city. Journal of the Korean Institute of Illuminating and Electrical Installation Engineers 24(6): 18-26.

31. Kuper, R. (2017) Evaluations of landscape preference, complexity, and coherence for designed digital landscape models. Landscape and Urban Planning 157: 407-421.

32. Lee, J., J. Yu and B. Kim(2004) Analysis of evaluation characteristics on lighting technique type of the exterior lighting in building. Journal of Architectural Institute of Korea: Planning 20(2) : 185-192.

33. Li, Q., Z. Huang and K. Christianson(2016) Visual attention toward tourism photograph with text: An eye-tracking study. Tourism Management 54: 243-258

34. Ngesan, M. R., and H. A. Karim(2012) Night time social behavior in urban outdoor spaces of Shah Alam. Procedia-Social and Behavioral Sciences 50: 959-968.

35. Ode, A., G. Fry, M. S. Tveit, P. Messager and D. Miller(2009) In- 
dicators of perceived naturalness as drivers of landscape preference. Journal of Environmental Management 90: 375-383.

36. Park, J., M. Oh and H. Kim(2009) A study on improvement of lighting environment of night-scope in Anyang-si. Journal of the Korean Institute of Illuminating and Electrical Installation Engineers 23(2): 27-35.

37. Pazhouhanfar, M. and M. Kamal(2014) Effect of predictors of visual preference as characteristics of urban natural landscapes in increasing perceived restorative potential. Urban Forestry \& Urban Greening 13(1): 145-151.

38. Pechanec, V., J. Brus, H. Kilianova and I. Machar(2015) Decision support tool for the evaluation of landscapes. Ecological Informatics 30: 305-308.

39. Qi, T., G. Zhang, Y. Wang, C. Liu and X. Li(2017) Research on landscape quality of country parks in Beijing as based on visual and audible senses. Urban Forestry \& Urban Greening 26: 124-138.

40. Qin, G, L. Mei zhen, M. Jin-hua, and Z. Jun-lei(2011) The development of urban night tourism based on the nightscape lighting projects: A case study of Guanzhou. Energy Procedia 5: 477-481.

41. Raymond, C. M., M. Kytta and R. Stedman(2017) Sense of place, fast and slow: The potential contributions of Affordance theory to sense of place. Frontier in Psychology 29: 1-14.

42. Rozado, D., A. E. Shoghri, R. Jurdak(2015) Gaze dependant prefetching of web content to increase speed and comfort of web browsing. International Journal of Human-Computer Studies 78: 31-42.

43. SensoMotoric Instruments(2012) Begaze Version 3.2 Manual. SensoMotoric Instruments

44. Slagter, H. A., K. Georgopoulou and M. J. Frank(2015) Spontaneous eye blink rate predicts learning from negative, but not positive, outcomes. Neuropsychologia 71: 126-132.

45. Song, D. and J. Yoon(2006) A study on the characteristic analysis of the visual preference on the urban streetscape: Focused on sampling of the preference-types and influence of primary factor. Journal of Architectural Institute of Korea: Planning 22(9): 243-250.

46. Strobele, M. and M. Hunziker(2017) Are suburbs perceived as rural villages? Landscape-related residential preferences in Switzerland. Landscape and Urban Planning 163: 67-79.

47. Suh, J. and Y. Choi (2012) Research on the visual cognitivity of urban plaza: Focused on preference and complexity. Korean Design Forum
34: 197-206.

48. Suh, J., J. Park, and J. Kim(2015) A comparative analysis of visual preference and cognitive processing characteristics using a eye-tracking method: With a focus on the 50 sites for rural development project. Journal of Digital Design 15(3): 335-343.

49. Surova, D. and T. Pinto-Correia(2016) A landscape menu to please them all: Relating users' preferences to land cover classes in the Mediterranean region of Alentejo, Southern Portugal. Land Use Policy, 54: $355-365$

50. Tagliafierro, C., M. Boeri, A. Longo and W. G. Hutchinson(2016) Stated preference methods and landscape ecology indicators: An example of transdisciplinarity in landscape economic valuation. Ecological Economics 127: 11-22.

51. van Zantan, B. T., P. H. Verburg, M. J. Koetse and P. J. H. van Beukering(2014) Preference for European agrarian landscapes: A meta-analysis of case studies. Landscape and Urban Planning 132: 89-101.

52. van Zanten, B. T., I. Zansada, M. J. Koetse, F. Ungaro, K. Hafner and P. H. Vernurg(2016) A comparative approach to assess the contribution of landscape features to aesthetic and recreational values in agricultural landscapes. Ecosystem Services 17: 87-98.

53. Wang, R., J. Zhao and Z. Liu(2016) Consensus in visual preferences: The effects of aesthetic quality and landscape types. Urban Forestry \& Urban Greening 20: 210-217.

54. Woo, K., and J. Suh(2017) Urban landscape image study by text mining and factor analysis: Focused on Lotte world tower. Journal of the Korean Institute of Landscape Architecture 45(4): 104-117.

55. Yoon, J. and K. Chung(2012) Residents of an apartment complex for lighting design study of affinity: Focused on pedestrian space and resting space. Korean Design Forum 34: 297-305.

56. Yeo, H., J. Suh and S. Kim(2012) An analysis of the visual preference and landscape image of historic-cultural landscape in the city: Mainly the external view poiint of Gyeongbok-Gung. Journal of Digital Design $12(3): 11-20$

57. Zhang, C., X. Wu, L. Zhang, X. He, and Z. Lv(2017) Simultaneous detection of blink and heart rate using multi-channel ICA from smart phone videos. Biomedical Signal Processing and Control 33: 189-200.

58. https://en.wikipedia.org/wiki/Eye_tracking

Received : 30 October, 2017

Revised : 03 December, 2017 (1st)

02 January, 2018

(2nd)

Accepted : 02 January, 2018

4인익명 심사필 